\title{
Heatmap3: an improved heatmap package with more powerful and convenient features
}

\author{
Shilin Zhao, Yan Guo, Quanhu Sheng, Yu Shyr \\ From UT-KBRIN Bioinformatics Summit 2014 \\ Cadiz, KY, USA. 11-13 April 2014
}

\section{Background}

Heat map and clustering are used frequently in expression analysis studies for data visualization. Simple clustering and heat map can be produced from the "heatmap" function in R language. However, it has some limitations in producing advanced graphics and is not highly customizable. Thus, we developed an $\mathrm{R}$ package heatmap 3 which significantly improves the original heatmap by adding more powerful and convenient features and providing a highly customizable interface.

\section{Materials and methods}

The heatmap3 package is developed based on the heatmap function in the R language and is completely compatible with it. All the commands and parameters for heatmap can also be used in heatmap3. At the same time, heatmap3 imported many new parameters to provide more powerful features. Heatmap3 also provided a highly customizable interface for users' own functions so that they can label and annotate the data in the figure very easily.

\section{Results}

The new features of heatmap3 include a highly customizable legend and side annotation, a wider range of color selections, new labeling features which allow the user to define multiple layers of phenotypes and automatically compute associations based on these phenotypes. Additional features such as different agglomeration methods for estimating distance between two samples are added for clustering. A simulated data is used to demonstrate the result of heatmap3 package (Figure 1).

* Correspondence: yu.shyr@vanderbilt.edu

Center for Quantitative Sciences, Vanderbilt University, Nashville, TN 37027, USA
Submit your next manuscript to BioMed Central and take full advantage of:

- Convenient online submission

- Thorough peer review

- No space constraints or color figure charges

- Immediate publication on acceptance

- Inclusion in PubMed, CAS, Scopus and Google Scholar

- Research which is freely available for redistribution 


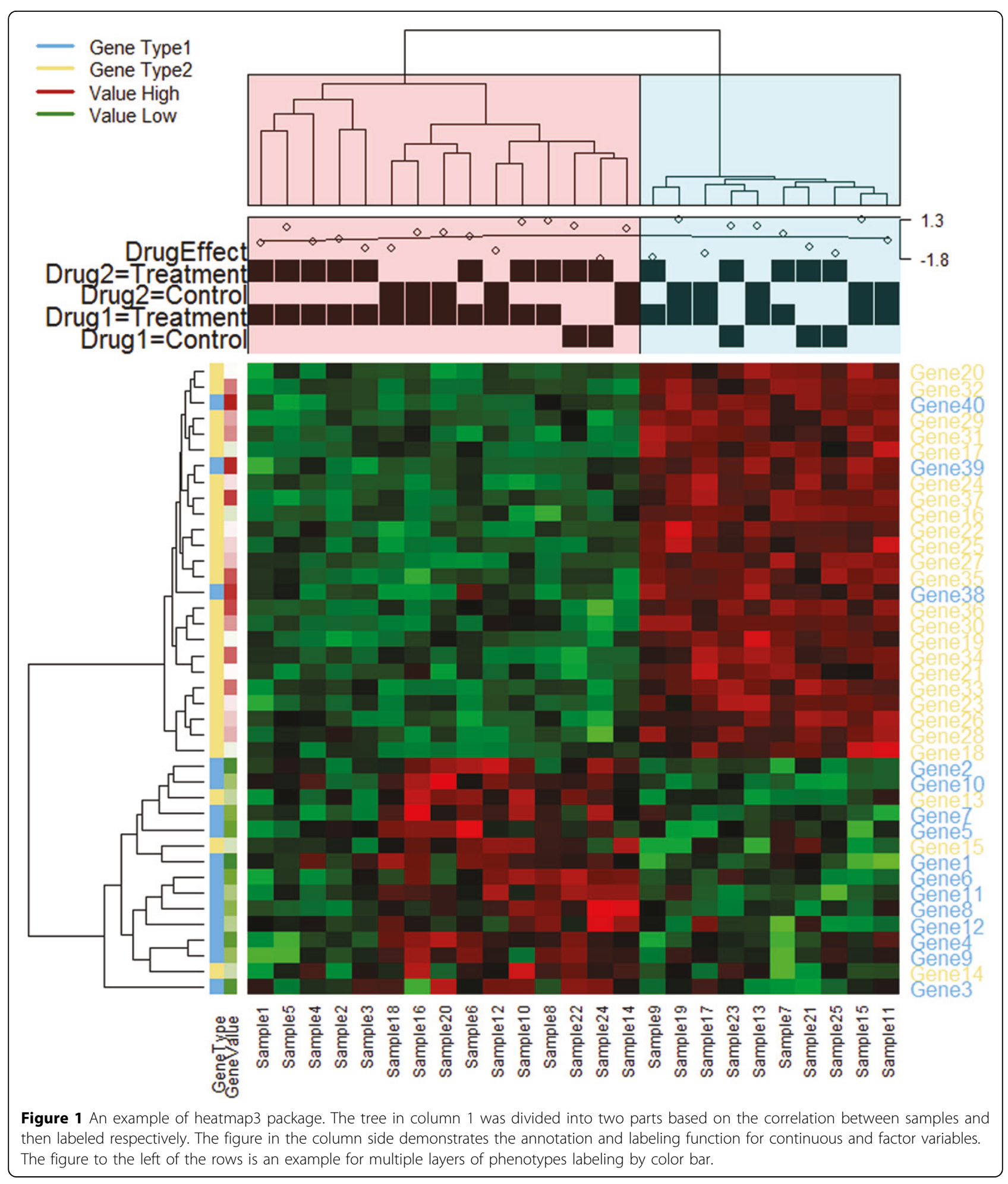

